\title{
A FORMAÇÃO DO CARÁTER DO ADOLESCENTE SOB A PERSPECTIVA DE EDITH STEIN
}

\author{
João Igor Moraes ${ }^{1}$ \\ Roseli Aparecida Mônaco ${ }^{2}$ \\ Silvia Helena Modenesi Pucci ${ }^{3}$
}

RESUMO: Este trabalho tem como objetivo compreender o caráter e os componentes da formação psicológica através do pensamento da filósofa Edith Stein. Com a noção de adolescência e desenvolvimento humano, os elementos externos como a vulnerabilidade social e a delinquência interagem com a identidade, as emoções e os valores para a construção de uma vida psíquica saudável, se orientados por uma estrutura interna. Conduzidos pela análise de um produto cultural, o filme Blackboard Jungle, de 1955, os problemas educativos permitem a base das reflexões sobre essa constituição da pessoa humana.

Palavras-chave: Adolescência. Individualidade. Emoções. Valores.

'Graduando em Psicologia (202I) pela Universidade de Santo Amaro - UNISA. Contato: joaoigoror8o@gmail.com.

2 Mestre na área de Educação, Arte e História da Cultura na Universidade Presbiteriana Mackenzie. Possui Master em Tecnologia da Educação pela American Intercontinental University, Pós-graduação em Psicopedagogia pela PUC/SP e graduação em Psicologia pela Universidade de Santo Amaro. Cursa atualmente especialização em Vincularidade de Casal e Família na Sociedade Brasileira de Psicanálise de São Paulo. É professora e Supervisora de estágios do curso de Psicologia Escolar da Universidade Santo Amaro (UNISA). Tem experiência nas áreas de Educação e Psicologia, com ênfase em psicologia da educação e do desenvolvimento, psicanálise e Educação, lúdico na Educação, educação a distância, atuando nos seguintes temas: psicanálise e Educação, psicologia escolar, dificuldade de aprendizagem, formação de professores presencial e a distância, prática de ensino infantil e fundamental, jogos e brinquedos na educação e psicologia, ensino e aprendizagem. Foi educadora do Laboratório de Brinquedos e Materiais Pedagógicos da Faculdade de Educação da USP (FEUSP). Foi professora do curso de Pedagogia e Psicopedagogia da Faculdade Paschoal Dantas. É psicóloga clínica e Psicopedagoga.

3 Doutora em Psicologia da Saúde pela Universidade do Minho, UMINHO - Portugal (com revalidação pela Universidade de Campinas / UNICAMP, setor Medicina - Brasil). Pesquisadora Membro do Grupo de Estudos de Jovens Investigadores da Sociedade Portuguesa para o Estudo da Obesidade (SPEO). Pesquisadora Colaboradora no Grupo de Pesquisa da Universidade do Minho / Portugal: Processos Psicológicos Individuais e Familiares em Saúde e Doença. Mestre pelo Programa de Pós-Graduação em Psiquiatria e Psicologia Médica - UNIFESP. Especialista em Psico-Oncologia pelo Hospital do Câncer/ SP, Especialista em Dependência Química (Universidade Federal de São Paulo/UNIFESP) e, Especialista em Promoção e Prevenção à Saúde em Álcool, Tabaco e Outras Drogas (UNIFESP). Coordenadora e Docente de Psicologia na Universidade Santo Amaro / UNISA - Brasil, em diversas disciplinas, bem como Supervisora hospitalar, Membro do NDE e atendimento junto alunos da Medicina - PAPU. Membro do Comitê de Ética e Orientadora de trabalhos científicos. Revisora de artigos Nacionais e Internacionais. Formação acadêmica: Doutora em Psicologia Instituição: Universidade de Santo Amaro- UNISA 
ABSTRACT: This work aims to understand the character and components of psychological formation through the thinking of the philosopher Edith Stein. With the notion of adolescence and human development, external elements such as social vulnerability and delinquency interact with identity, emotions and values to build a healthy psychic life, if guided by an internal structure. Conducted by the analysis of a cultural product, the film Blackboard Jungle, from 1955, educational problems provide the basis for reflections on this constitution of the human person.

Keywords: Adolescence. Individuality. Emotions. Values.

\section{INTRODUÇÃO}

Segundo dados do Instituto Brasileiro de Geografia e Estatística - IBGE (2020) a tendência dos adolescentes de famílias com menos rendimento per capta a estarem escolarizados é de um desfalque de cerca de 32,5\% em relação a famílias de maior renda, e até mesmo por volta de $28,6 \%$ dos adolescentes estão em distorção de idade-série ou fora da escola. Além disso, dados como infraestrutura das escolas, condições precárias de saúde ou famílias em vulnerabilidade também contribuem para radicalizar os números de uma realidade cultural em sérios problemas.

Considerando que a adolescência é o primeiro momento onde a liberdade para a autodeterminação pode acontecer e, contrapondo a isto, estando sujeita aos conflitos e adversidades para sua própria saúde psicológica, é importante que se reflita sobre como melhor entende-la e aperfeiçoa-la, tendo como objeto a pessoa humana em sua totalidade e em seu sentido último. Tópicos como identidade, emoções, valores saltam como elementos de análise dessa conjuntura.

A particularidade de se estudar um objeto que é parte do próprio sujeito acarreta dificuldades que apenas uma análise minuciosa e profunda pode transpor. É precisamente o significado da pessoa humana que compõe os escritos da filósofa Edith Stein e que, pelas suas investigações fenomenológicas, desvelará uma antropologia integral, ao agregar os estratos do corpo (Körper), alma (Psych) e espírito (Geist) e formaliza-los em definição própria.

Transpor essas adversidades não pode estar aquém de um olhar para a pessoa e para a sua interioridade. Embora transtornos no que se referem a pensamentos, emoções e atitude de vida, ocorrem, para usar as palavras de Edith Stein "quando se 
resiste a sua própria direção ontológica” (STEIN, 1932-1933/2003), um verdadeiro trabalho formativo é necessário para orientar a estrutura da pessoa humana e suas potências, sustentando uma vida saudável em sentido amplo.

Com uma leitura atenta da obra da filósofa é possível extrair os conceitos e reflexões que ajudem a pensar a adolescência. Em conjunto com a análise de um produto cultural, o filme Blackboard Jungle, ou Sementes de Violência, a apropriação autoconsciente que, nessa etapa, o jovem opera de si mesmo se torna mais compreensível e passível de estudo.

Diante de todo esse escopo, o presente trabalho visa compreender o processo de formação de elementos do carácter sob a perspectiva da antropologia de Edith Stein, com foco na identidade, dinâmica emocional e valores, tendo como referência o desenvolvimento humano do adolescente e seu contexto de vulnerabilidade social. Além disso, poder fornecer material para reflexão sobre a importância do pensamento steiniano para as áreas da psicologia da educação e psicologia do desenvolvimento.

\section{ANTROPOLOGIA FENOMENOLÓGICA DE EDITH STEIN}

A fenomenologia, fundada por Edmund Husserl (1859 - 1938) é um método filosófico que permite o questionamento da percepção dada da realidade e o "retorno às coisas mesmas”, à essência dos fatos, mediante um procedimento e uma análise pela consciência. (BELLO, 2006; ESPÍNDULA, 2019). Nesse buscar da essência, dessa redução fenomenológica, denominada "epoché", o sujeito suspende sua relação natural com o mundo e começa pela redução eidética, de onde eidos ou "ideia", a análise e desvelamento do sentido dos entes e atos.

O mundo que se manifesta é vivido e captado por um sujeito, e essa apreensão são as vivências, a "erlebnis", que consiste em ter consciência dos atos que são por nos captados (BELLO, 2006). As vivências podem ser de ordem sensória, como o ato de ver ou ouvir, de ordem psicológica, como o sentir e, em um terceiro momento, há o registro dos atos, na redução fenomenológica, ou redução transcendental, refugiandose na investigação dos objetos que se apresentam à nossa consciência em si 
(PENNA; 200I).A proposta da Fenomenologia é ocupar-se, do sujeito transcendental - resquício da redução eidética, o sujeito que foi abstraído da realidade, ou seja, "eu" puro, autor das vivências (SILVA, C.; ESPÍNDULA; SILVA, P.,2019).

Esse recolhimento na consciência traça o percurso a uma estrutura interna que forma o sujeito. A partir disso, aponta Bello (2006) que a psicologia que se constitui como psicologia humana não pode se desconsiderar do que particulariza o ser humano propriamente, e isso ocorre com sua dimensão "espiritual”, ou de um "eu" com consciência e interioridade.

Edith Stein (I891-1942), filósofa, tendo sua tese de doutorado sob orientação de Edmund Husserl em Göttingen, no ano de 19ı6, assenta sua reflexão sobre o pensamento fenomenológico, investiga essa dimensão da interioridade e harmoniza sua obra em uma antropologia com forte traço religioso, morrendo como mártir na Segunda Guerra (KUSANO, 2009). Sua obra abarca a epistemologia e a ontologia da escola fenomenológica conjuntamente com a filosofia medieval de Tomás de Aquino (1225 - 1274) e com a mística espanhola do século XVI (KUSANO, 2009).

O pensamento de Edith Stein despontou no Brasil por volta da década de cinquenta, com trabalhos de tipo biográfico, apenas alcançando ao final da década de oitenta uma visibilidade maior, envolvendo os aspectos pedagógicos, filosóficos e antropológicos da autora (GOTO; GARCIA, 20I2). A psicologia que propõe a autora não é estritamente empírica, mas embasada em uma subjetividade com estrutura medular e uma descrição essencial (ESPÍNDULA, 2009). Uma das distinções mais importantes da individualidade humana é sua tripartição constitutiva da pessoa em corpo, alma e espírito (ESPÍNDULA, 2009;SILVA, 2011; KUSANO, 2009).

Para designar o corpo, há a distinção entre Körper e Leib, sendo aquele o corpo físico em si, radicado no mundo e proporcionando a diferenciação de si e do outro, e este, o corpo vivo, orgânico, capturado pelas sensações e, também, onde se expressa o que vem de dentro (KUSANO, 2009).

O espírito é aquilo que a interioridade humana tem de mais elevado e, por um lado sendo o centro do sujeito, da pessoa, e por outro, permeando até sua corporeidade, delineia-se como a sede da capacidade reflexiva e volitiva, possuindo 
por excelência a qualidade da liberdade (KUSANO, 2009). Segundo Bello (2006), o estrato "espiritual" do ser humano se refere àquilo que o distingue dos outros seres naturais e constitui propriamente sua identidade. É preciso apontar a diferença entre a sua delineação singular, pessoal, e o espírito Divino ou o espiritual Ilimitado, dado que este é o estrato

de onde conhecemos a realidade daquilo que nos supera e ultrapassa, consistindo em algo Potente e Absoluto (BELLO, 2019).

Vale enfatizar a questão de tradução dos termos, na qual, pela versão em inglês da editora estadunidense "Institude of Carmelite Studies" o termo alemão "geisting" usado por Stein, significa "mental" - mental - e o termo "Geist", significa "mind" - mente (STEIN, 1922/2000). Nas traduções em espanhol das obras completas, pela impressão da editora Monte Carmelo, nota-se que a opção de "mental" por "espirituale" e "mind", por "espíritu"(STEIN, 1932-1933/2006). Não se deve, contudo, haver confusão. Como colocado anteriormente pela professora Ales Bello (2006) o termo "espiritual" quer dizer o eminentemente humano, e é essa a perspectiva que está sendo adotada neste trabalho.

Quanto à instância da alma, ou psique, há uma consideração sobre a terminologia que Stein se utiliza para se exprimir, na qual a palavra Seele vem designar a espacialidade da alma onde se radica as propriedades psíquicas (KUSANO, 2009), e onde a autora também indica que a alma é formada pelas forças da psique e do espírito (ESPÍNDULA, 2009). O espirito, a pessoa em si em sua interioridade, é caracterizado de forma basilar pela reflexão e vontade (STEIN, 1917/2006), ou seja, respectivamente pela consciência apropriada de si e de suas vivências e pela determinação própria dos atos de sua estrutura interna.

Em respeito ao psíquico, também, fica definido que a "alma" é a interioridade, enquanto a "psique" faz parte da mesma, junto com o corpo e o espírito (KUSANO, 2009; SBERGA, 2015). Estabelecer essa terminologia é muito importante, pois nos reenvia ao ponto de separação entre a psicologia entendia como causalidade natural, determinada de maneira fisiológica e social, e a psicologia "com alma", aberta e integrada sob a ação direta do espírito - vontade e reflexão distintas. 


\section{DESENVOLVIMENTO DO ADOLESCENTE E CARÁCTER}

A constituição da subjetividade na adolescência perpassa, não somente as alterações hormonais e dimensões físicas, mas também as competências cognitivas e sociais, autonomia, autoestima e intimidade, onde os objetivos e motivações estão à volta dos conflitos e experiências dos jovens à luz de barreiras culturais e educacionais (PAPALIA; FELDMAN 2013).O conceito de adolescência foi trabalhado de diferentes maneiras pelos autores contemporâneos.

De maneira global a fase da adolescência foi tida como semi-patológica e sempre marcada por dificuldades, naturalizando conflitos em um âmbito universal e abstrato (BOCK, 2007). Buscando debater a posição da adolescência como uma fase sempre patológica, há a visão de base liberal, que considera haver um homem apriorístico dentro de cada um de nós, um homem em potencial com seu desenvolvimento previsto pela sua própria condição de homem (BOCK, 2007), no qual a sociedade oferece suporte para sua realização. No desenvolvimento humano, a adolescência foi revista como integração de fatores biológicos, contextos sociais, tempo histórico e, atualmente, a participação ativa do jovem na sociedade é preconizada, assim como o reconhecimento de suas habilidades (SENNA, 2012).

O fator ambiental é muito importante, ainda que não determinante, no aparecimento das faculdades internas do individuo, e dadas às dificuldades do amadurecimento que perpassa a adolescência, além dos elementos psicossociais vinculados a situação econômica, violência ou organização social fraca (PAPALIA; FELDMAN 2013). Em síntese, nota-se que durante a adolescência o desafio central é passar de uma indefinição ou definição a partir de fora, para uma definição a partir de dentro, descobrir uma verdade pessoal mais profunda (BAUNGART; AMATUZZI, 2007). Essa verdade pessoal não é possuída sem momentos de certo conflito interno.

O pensamento abstrato e as mudanças corporais serão fundamentais para constituição do autoconceito, auto-estima e identidade do adolescente, ainda que aspectos biológicos e fisiológicos não forjem sua individualidade (XAVIER; NUNES, 2015). Edith Stein (1932-1933/2006) irá aprofundar ainda mais a reflexão, 
colocando que existe uma diferenciação - mas não uma disjunção - entre os atos da psique em relação aos atos do espirito. Tem-se então que, em realidade, os estados fisiológicos e os dados psicológicos por si mesmos não constituem a unidade total do carácter do adolescente que vive as transformações de sua fase de desenvolvimento.

Nesse ponto, há uma definição a ser feita a respeito dos temos "personalidade" e "carácter". Comumente usados de forma intercambiável, eles denotam realidades muito próximas e parecidas. Segundo o dicionário da American Psychological Association - APA (2020a), o carácter traz a ideia da totalidade dos atributos, enquanto a personalidade, a configuração das características (APA, 2020c). Edith Stein (1932-1933/2006) escreve que a peculiaridade da pessoa é sua personalidade, e o carácter pode ser interpretado como a disposição das qualidades internas.

$\mathrm{Na}$ análise precisa de Edith Stein se insere a própria etimologia da palavra “carácter", que do antigo grego kharásso denota "riscar" ou "gravar" (CHARACTER, 2021). Isso porquê, segundo a autora, o indivíduo em sua completude não é constituído apenas pelo carácter, pois este mesmo tem como sua direção e seu centro o espírito, a pessoa em si, e se forma com as atitudes habituais do cento da afetividade e da vontade (SBERGA, 2015), ou seja, com as atitudes impressas, gravadas, adquiridas.

As emoções e a motivação podem configurar elementos do carácter que, atravessando a adolescência, acentuam a atualização e desenvolvimento da pessoa. Com sua compreensão, essa fase tende a se tornar mais saudável.

\section{PSICOLOGIA DAS EMOÇÕES}

As emoções e a vida emocional constituem um dos elementos mais importantes na estruturação da pessoa humana. Embora sejam feitas diferentes concepções do conceito de emoção nos campos da filosofia e da psicologia, a sua realidade experiencial é muito próxima das vivências cotidianas e inabituais do indivíduo.

Muito acertada é a definição de emoção pela APA (2020b) que a coloca como um padrão de resposta determinado qualitativamente e pessoalmente pelo significado 
de dado evento. Antes se explorar qual a dimensão que o termo "pessoal" ganha à luz do pensamento steiniano, é útil situar mais acuradamente o diversificado conceito de emoção.

Tendo em vista esclarecer essas diferentes concepções, Scarantino e de Sousa (202I), traçam três linhas-mestras para separar as emoções em uma Tradição dos Sentimentos, uma Tradição Avaliativa e uma Tradição Motivacional. Segundo os autores, essa separação busca explanar para a psicologia contemporânea os sentidos que as emoções possuem a partir de seus componentes. A primeira e a última, tendem a enxergar as emoções como sentimentos em uma forma própria independente da razão e da sensibilidade ou como um estado que tende a um comportamento e um ato, respectivamente.

A tradição Avaliativa propõe que um intercurso cognitivo, de avaliação é preciso para estabelecer uma relação conceitual entre a emoção e seu objeto formal. É nesta perspectiva que a teoria das emoções de Edith Stein parece melhor se encaixar, mas seria melhor enquadrar seu pensamento na corrente que Scarantino e de Sousa (202I) denominam como a Tradição Híbrida Sentimento-Avaliativa. Dessa maneira, visando melhor inter-relacionar os aspectos que configuram fenomenologicamente as emoções, nesta corrente se propõe que elas sejam subdivididas como sentimentos avaliativos, e isso a aproxima da ideia de Stein de que tanto a presença da consciência racional quanto o estrato anímico da vida psíquica estão ativamente juntos.

Edith Stein identifica que existem graus ou níveis de profundidade do que toca ou do que se produz na vida interna de uma pessoa e, em certa medida, os definem (SZANTO; MORAN, 2020). Em se tratando da esfera da afetividade, o nível mais externo é composto das sensações, seguido dos sentimentos comuns (estados afetivos do corpo vivo), dos humores e então das emoções, que, se se pode dizer, ocupam a quarta posição em um estrato que vai mais exteriormente da percepção do corpo até o repouso no "Eu puro", Das reine Icht.

Em um próximo nível, ainda, Stein coloca os sentimentos, que são atitudes dirigidas a outras pessoas (SZANTO; MORAN, 2020). Com o propósito de não cair em um nominalismo, convém assinalar que embora sob o nome geral de emoções, as 
linhas-mestras acima mencionadas abarcam de forma particular também outros níveis elencados por Edith Stein, embora de maneira difusa e sem o sentido que ela os caracteriza.

A reunião dos movimentos da afetividade ocorre no ânimo, Gemüet, componente da alma humana. Nele estão presentes as dinâmicas afetivas bem como a qualidade cognitiva de valoração transformada em um posicionamento pessoal e de ação (SBERGA, 2015). O ânimo está disposto a receber as influências através da vontade e da razão assim como influencias da esfera da afetividade e, por sua vez, a consciência e a interioridade do eu podem conduzir e direcionar a ambas.

Não é a presença de um ambiente, de ações e exemplos bons meramente observáveis que vão formar propriamente uma pessoa, mas sim a apropriação por parte desta do mundo objetivo dos valores que se sobrepõe e se mostram (STEIN, 1922/2006). Nesse sentido, existe uma circularidade entre os conceitos razão e afetividade, na medida em que a primeira reconhece ou apropria os valores enquanto a ultima provê o tônus para sua efetivação no mundo concreto. Para Stein a afetividade não direcionada está aberta por um mero contágio (SBERGA, 2015) e é marcada pela superficialidade - palavra adequada a este contexto steiniano, pois a dispersão das emoções ocorre opostamente ao aprofundamento em si mesmo.

É possível perceber que as emoções estão intrinsecamente ligadas aos valores no pensamento de Edith Stein; e é certo que nas vivências da afetividade se manifestam as relações existentes entre a intencionalidade da motivação e os valores, imbuídos de sentido (Sinn). Nas palavras da autora "a apreensão de um valor pode motivar uma disposição (por exemplo, a alegria na beleza) e, com isso, um querer e fazer (talvez a realização de um estado de coisas reconhecido como moralmente correto)" (STEIN, 1922/2000).

\section{MOTIVAÇÃO E VALORES}

Assim como a causalidade natural é própria das vivências corporais e a causalidade psíquica das vivências anímicas, a causalidade motivacional, ou motivação (Motivation), é própria das vivências intencionais do espírito. $O$ nexo 
entre estas últimas é estabelecido levando em conta o tipo de vivência e o tipo de doação do objeto à consciência, bem como o sentido que o objeto carrega (PERES, 2019).

Para esclarecer esse nexo entre causalidade e motivação, se pode tomar como exemplo a vivência imaginativa de um livro que se leu há alguns dias, onde a doação rememorada imaginativa evoca estados de ânimo como contentamento por ter aprendido algo com o livro e, conjuntamente, o valor (e sentido) do aprendizado como algo bom e edificante. Este último se dá quando um objeto das vivências, o motivo, suscita uma relação de sentido emergindo uma motivação. Essa relação acontece, naturalmente, pela intencionalidade, enquanto que a relação de sentido abre espaço para um leque de diferentes respostas, nas quais se insere a dimensão dos valores (SZANTO; MORAN, 2020).

Vale ressaltar que o eu empírico é objeto da psicologia e, portanto, não pode desacompanhar o fluxo de vivências e, sendo assim, a possibilidade de apreendê-lo é através da abertura da dimensão do "eu". Esta apreensão corresponde ao terceiro passo na experiência das vivências. Nesse sentido, não se deve ter por consequência que Edith Stein esteja traçando um determinismo psíquico, pois a realidade causal psíquica recebe influencias de diferentes instâncias e aspectos espirituais (geistige) tem tanta força ou mais que somente os sensíveis na corrente de consciência.

De acordo com a definição da APA (2020d) os valores podem ser considerados como "um princípio moral, social ou estético aceitos por um indivíduo ou sociedade como um guia para o que é bom, desejável ou importante”. É justamente a infusão desse aspecto espiritual que confere aos motivos, ou valores, sua nobreza, a inclinação da vontade para capta-los e sua relevância.

\section{METODOLOGIA}

O objeto primário de estudo deste trabalho é a obra de Edith Stein e, para o intercurso em seu pensamento, a metodologia central é a revisão bibliográfica integrativa, que consiste na pesquisa teórica e a leitura dos textos da autora. Artigos e livros sobre a obra de Stein, tanto em português, quanto em língua inglesa, foram 
buscados em base de dados como Scielo e Pepsic, bem como ficheiros de artigos encontrados com base em pesquisa Google, com uso das palavras-chave: Edith Stein, educação, pedagogia, psicologia, education, pedagogy, psychology e theology. Traduções das fontes primárias também foram consultadas.

Com a finalidade de aprimorar, melhor fundamentar e mesmo exemplificar a repercussão concreta da obra, traçar relações com um objeto cultural foi uma proposta que se somou ao trabalho. Assim, foi realizada uma análise crítica do filme norte-americano Blackboard Jungle, de 1955, cujo tema é a educação. Além de repassar o filme observando pontos de vinculação entre o pensamento de Stein e a narrativa, foi feito um tópico que intenta mostrar a complementaridade desta com a terceira fase da obra da autora e seu pensamento educativo tardio, tendo, assim a espiritualidade e a teologia como resposta e suplemento para as problemáticas identificadas.

\section{ANÁLISE}

Filmado em 1955, o longa-metragem Blackboard Jungle, em português traduzido como Sementes de Violência, registra o drama de um ex-soldado e então professor de língua inglesa, Richard Dadier (ator Glenn Ford), recém-chegado a uma escola estadunidense após a Segunda Guerra Mundial e na qual tem por missão conquistar uma turma de adolescentes rebeldes ao sistema educativo. Os jovens apresentam comportamentos de risco, como uso de álcool, violência, criminalidade, intolerância à escola e à aprendizagem.

Inaugurando a temática focada em estudantes, o filme retrata pela primeira vez no cinema os dramas de um professor convidado a abandonar sua tarefa e os conflitos sociais emergentes sob a ótica das políticas educacionais vigentes (PERLSTEIN, 200o). É possível estabelecer um paralelo que marca o estado da cultura no pós-guerra a partir de suas vicissitudes e as teorias de Edith Stein que, além de tê-la vivenciado, refletiu sobre as dificuldades as quais professores, alunos e jovens no geral estariam sujeitos poucos anos adiante. 
Por sua capacidade visual, sonora e dramática, alguns temas da época ganham relevância e reconhecimento também para a atualidade. Existem estratégias para a análise de um filme e dentre elas a análise de conteúdo se mostra efetiva para um levantamento temático, pois permite selecionar cenas nos quais assuntos e sentidos próprios são retratados (PENAFRIA, 2009).

Sendo assim, a seleção de três cenas do filme ganha evidência para compreender o papel da pessoa humana nesse contexto, e se identificam em três categorias: I - construção da identidade, 2 - mau direcionamento das emoções no adolescente, 3- motivações e valores. A enumeração delas não obedece a uma sequência temporal interna do filme, mas é feita com base em um critério de organização da análise.

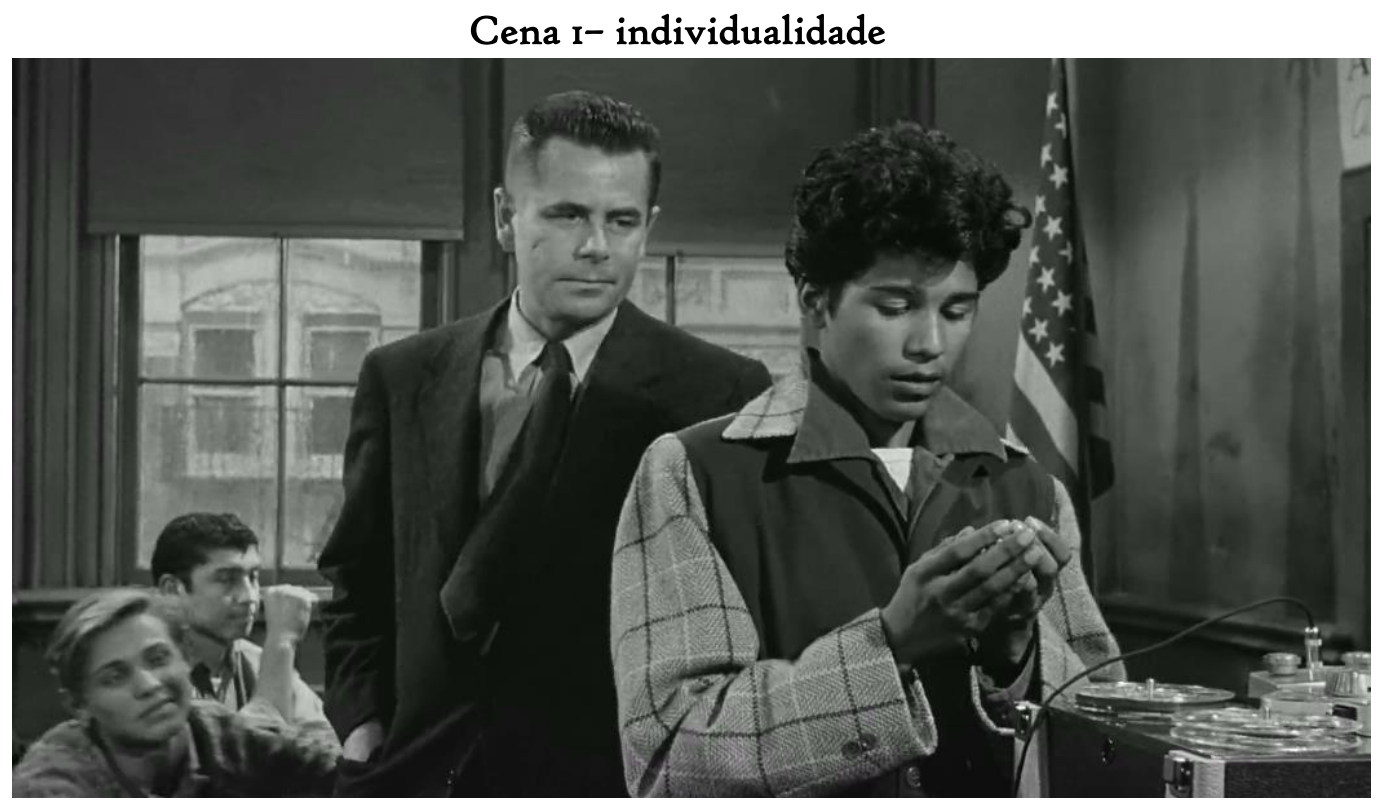

Fonte: Blackboard Jungle (1955)

$\mathrm{Na}$ cena, enquanto caminha para sala de aula, o personagem principal dialoga com um delegado sobre uma briga ocorrida anteriormente, entre um aluno que tentava prejudicar uma professora, e o próprio Dadier. O personagem principal alega não ter conseguido identificar o responsável, enquanto o policial retoma sua experiência com casos de delinquência, mostrando que comumente esse perfil de 
adolescente possui pais ausentes e vulnerabilidade social, pelo que o líder da gangue assume esse papel de autoridade aos jovens “confusos, desconfiados, assustados”. Em seguida, após despedir o oficial e já em aula, o professor pede a algum dos jovens a realizar uma gravação de voz, e os alunos indicam seu colega Morales (ator Rafael Campos) para falar.

Então, a pedido do professor, Morales, de origem latina, provavelmente filho de imigrantes que moram nos subúrbios, relata, em um instrumento de áudio, seus afazeres do dia antes de chegar à escola. Em sua fala, descreve como acordou, se arrumou e tomou o ônibus. A principal questão a ser levantada nessa cena é sobre a individualidade. Assim, se torna impossível discernir qualquer individualidade através da fala do delegado no que tange aos adolescentes. A irredutibilidade da pessoa a atributos relacionais ou sociais assinala isso.

A violência está associada a um processo identificatório no jovens, onde ideais sociais são atingidos sob a posse abruta de objetos e posições (ZAPPE, 2010). Dessa maneira, apenas com a fala de Morales se pode obter vivências que são validadas e fixadas, dado o fato de que o jovem as reúnem em torno de um sentido e essencialidade própria, haja vista que para Stein o mero contágio comportamental não revela as camadas pessoais (NUNES, 2019). Além disso, tanto Morales quanto os adolescentes que o delegado comenta estarem sem figuras parentais próximas estão, por isso mesmo, potencializados pelo que o teórico da psicologia da identidade James Marcia denomina difusão de identidade (HALL; LINDZEY; CAMPBELL, 2007), ou seja, a falta de compromisso e equilíbrio.

Para Edith Stein a espécie ou a denominação mais universal de uma dada forma precisa de atualização em uma individualidade (SHARKEY, 2009). Nesse sentido, o que permite se criar uma base para o indivíduo em si não é o fluxo contínuo de suas vivências, mas a apreensão coordenada das vivências em relação a uma forma individual, ao "eu", isto é, a reflexão ou um olhar dirigido para a interioridade (NUNES, 2019). É com isso que os múltiplos processos identificatórios e a difusão são, sem completa anulação, repostos por uma base, um fundo consistente ou perdurável. 


\section{Cena 2-emoções}

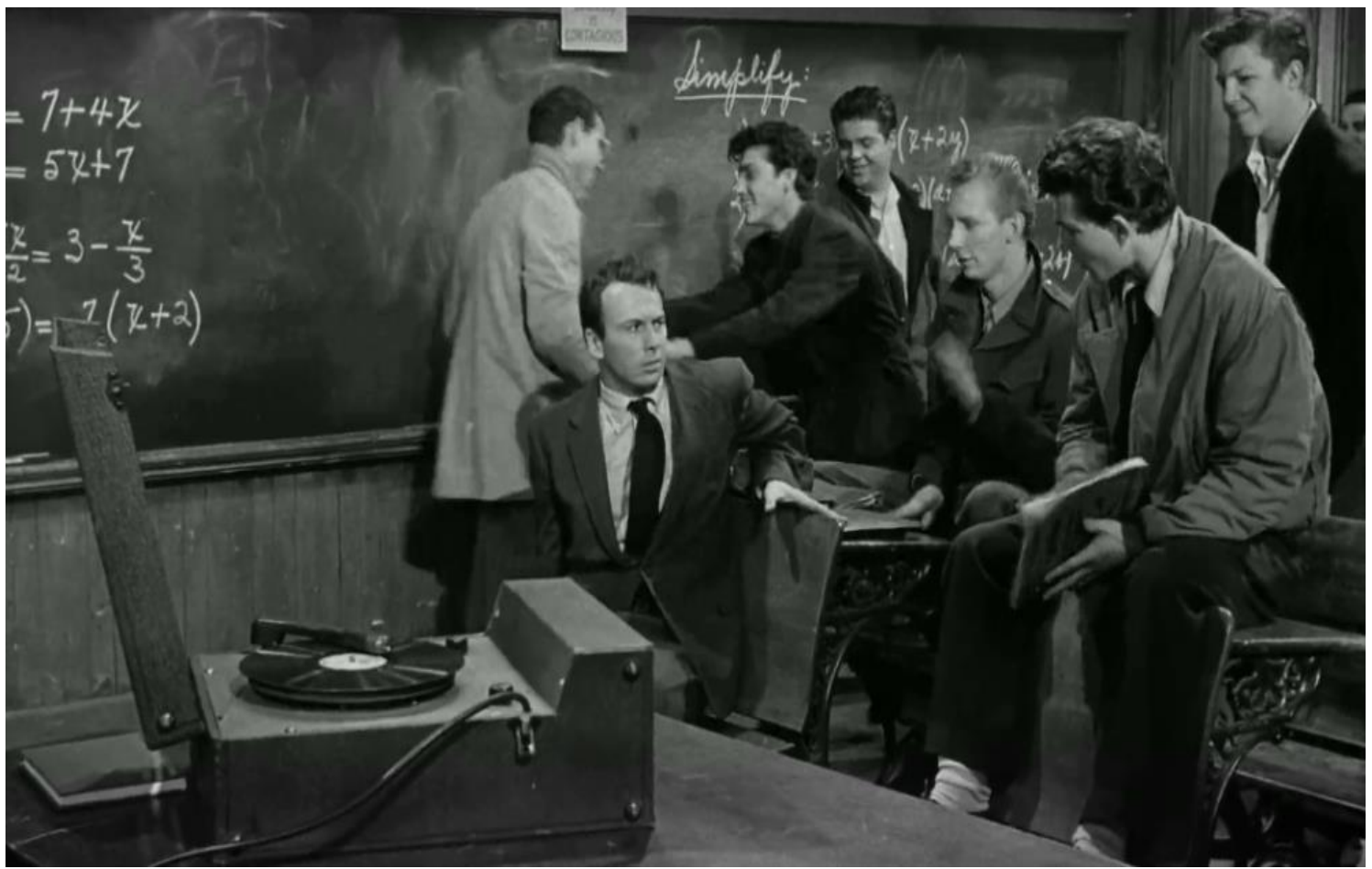

Fonte: Blackboard Jungle (1955)

$\mathrm{Na}$ cena onde o professor Joshua Edwards (ator Richard Kiley) concorda com a proposta dos alunos ouvirem os discos de música é possível observar a expressão da vitalidade e das emoções.

Edith Stein concorda que os movimentos corporais são anúncio das emoções (STEIN, I9I7/2006), mas também é preciso lançar mão do fato de que durante o ato da confusão algumas etapas na vivência e sua resposta podem ser notadas. Nas categorias das vivências, os alunos recebem o estímulo sonoro - nível da sensibilidade - e o ligam a um furor e euforia - nível da afetividade -e a partir disso, exercem o comportamento de quebrar os discos e dançar - ação. Embora acompanhando a cena pela primeira vez se chegue a conclusão que os jovens sentiram apenas raiva, uma observação acurada permite entrever que é a raiva e a agressividade são más disposições do carácter dos alunos, que se tornam atualizadas ou presentes no contexto, mas o estado emocional deles é mais complexo: a alegria, 
como base da euforia, também deixa sua marca. A música teve um efeito expressivo, mas não evocativo.

Segundo Stein (1922/2006) o conteúdo de um impulso pode afluir para a esfera psicofísica e eliciar certa disposição de ânimo como um acontecer cego ou um fato motivado racionalmente. A fala do professor "eu não entendo" ao final da cena pode ser explicada quando se percebe que o conteúdo implícito da pessoalidade, da liberdade e presença de espírito da individualidade dos alunos foi subsumida, e não sentiram-se tendo a emoção.

Stein escreve que toda emoção precisa de uma descarga, e que a conexão entre a emoção e sua expressão não é uma relação causal, mas de sentido, isto é, a expressão física da emoção é uma possibilidade assim como é a motivação de um ato correspondente da vontade (STEIN 2017/2006). Seguindo esse raciocínio a euforia pode ser expressão de uma raiva ou alegria, assim como estas podem motivar a vontade para a busca de um bem para o grupo.

Para isso, é importante a dupla compreensão de Edith Stein de que a influência direta, impensada, do ambiente no comportamento é desvantajosa e subtrai a liberdade, assim como a autora evidencia a necessidade da individualidade passar por uma auto-formação, uma estruturação de si (SBERGA, 2015), enquanto recebe do exterior os materiais para esse desenvolvimento, que no caso são a música e os afetos, ou seja, é preciso mobilizar as capacidades internas da pessoa para acolher e ordenar esses elementos.

Todavia, é indelével o fato de que, uma emoção pode se tornar uma qualidade habitual (STEIN, I917/2006) e, sendo assim, tanto o carácter expressivo dos jovens é consolidação de suas emoções de raiva ou alegria, quanto as músicas do professor podem repercutir de maneira formativa posteriormente quando o mundo dos valores for reaberto para reflexão. A mera ativação emocional não trouxe aos alunos equilíbrio emocional, pois sua vontade e sua capacidade reflexiva, ou o espírito, segundo Edith Stein coloca, não se presentificou intervindo e ordenando a vivência. 


\section{Cena 3 - valores}

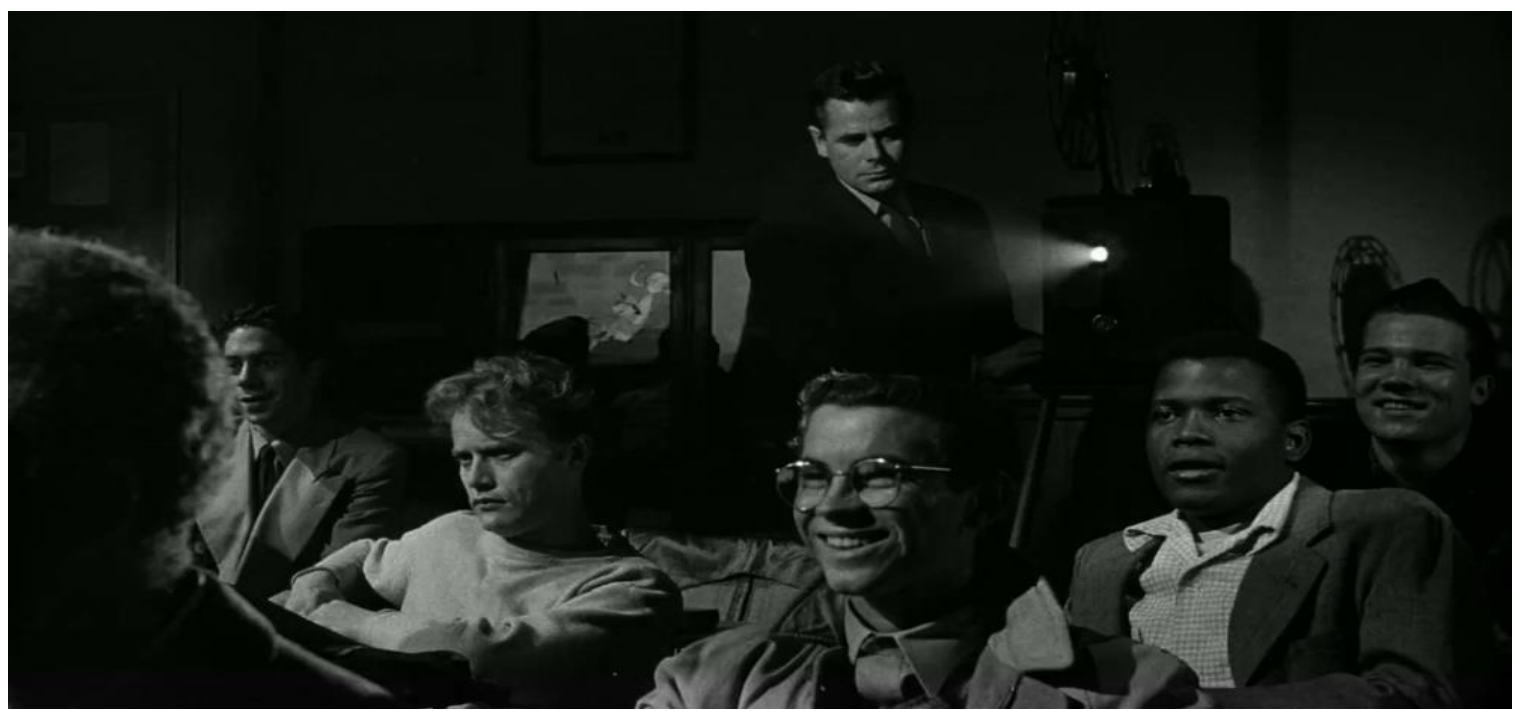

Fonte: Blackboard Jungle (1955)

Nessa cena Dadier busca uma didática que abra caminho para a reflexão e o pensamento crítico de seus alunos. Todos se mostram interessados ou, precisamente, motivados pelo filme exibido, e isso é indicado mesmo por Artie (ator Vic Morrow), um dos alunos mais violentos da classe, que, ainda que não elogie, dirige críticas ao objeto de sua atenção. Enquanto técnica para expressão das visões de mundo, posicionamento e debate, o filme exibido foi excelente.

Os comentários dos alunos podem ser entendidos como metáforas de sua própria condição social e psicológica. Quando os alunos dizem que o personagem do filme era um ladrão, o julgamento de bom ou mal depende da análise dos seus próprios carácteres, pois o carácter é a camada exterior do mesmo "eu”, pessoa, que se motiva especificamente. Ainda que não de forma originária, no ato empático, todavia, pode ocorrer a captação ou a presentificação das características do outro (NUNES, 2019).

Nesse sentido, um paralelo pode ser feito entre a teoria psicológica dos valores de Maslow e uma leitura steiniana da fala dos alunos. A primeira afirma que não há predominância entre as necessidades de deficiência - fisiológicas, segurança, amor e estima - em relação a auto-realização, embora haja uma tendência dessas mesmas 
necessidades básicas se sobreporem no nível de busca e imediatismo (HALL; LINDZEY; CAMPBELL, 2007). Para Edith Stein o chamado à auto-realização acontece de maneira permanente mesmo quando as necessidades, ou valores mais básicos estão presentes.

Nesse contexto, o próprio fato das falas emergirem denota a presença do mundo dos valores de maneira intrínseca, pois, para Edith Stein os valores apontam para um "eu”, uma pessoalidade, que os constitui. Não é a pessoa que instaura os valores arbitrariamente, mas a partir da estrutura humana como ser não meramente psicofísico, os valores são encontrados. As motivações, ou valores, mais espirituais são, por conseguinte, mais elevados na ordem dos bens, pois a própria pessoa, a pessoalidade, é espiritual (NUNES, 2019).

Dessa maneira, quando os alunos se indignam, dizendo "ele era um ladrão", estão, como pode confirmar o próprio engajamento do professor, comentando sobre suas própria hierarquia estabelecida de valores e criticando-a para dar lugar ao que o teórico Maslow denomina meta-necessidades, ou Valores-do-Ser (HALL; LINDZEY; CAMPBELL, 2007), como a verdade, beleza, bondade que para Edith Stein são influxos que devem ser recebidos na interioridade.

Uma das tarefas da escola é buscar fazer os alunos se esforçarem não por meio de recompensas extrínsecas, mas para alcançar os valores de motivação intrínseca, isto é, aqueles que reconhecem as necessidades individuais e coletivas (LICKONA, 2006). A proposta de Dadier aos alunos está fora dos padrões ordinários da escola; tanto o envolvimento e atenção deles com o filme mostram isso quanto sua própria separação entre seu discurso e dos outros professores. Se os adultos na escola não compartilham dos bons valores, se comprometer em transmiti-los aos alunos se dificulta, há o risco do próprio ambiente omitir a cooperação (LICKONA, 2006) e, além disso, a reflexão sobre a motivação reforça a busca desses valores.

\section{CONSIDERAÇÕES FINAIS}

A recepção do pensamento de Edith Stein no Brasil é recente, não abarca muitos anos de divulgação e produção acadêmica, embora seja uma autora 
polivalente, com contribuições para psicologia, filosofia e teologia. A sua educação filosófica como membro do circulo fenomenológico do século XX é complementada ou, mais, é fundamentada ao longo de sua obra nas ideias da filosofia antiga e medieval, com sua cosmovisão que busca restaurar, em vista da época em que a autora viveu e também a nossa, a concepção do ser humano como pessoa, de valor intrínseco e chamado à liberdade de sua própria essência, que se posiciona acima das determinações biológicas e sociais.

Resgatar certas noções presentes nos conceitos de corpo, alma e espírito é uma forma de tornar presente para o campo da psicologia dimensões integradas e indispensáveis para sua teoria e práxis. Assim, através da análise das três cenas do filme Blackboard Jungle, traços muito próprios da adolescência puderam ser destacados e colocados em relação com concepções da psicologia contemporânea e o pensamento de Edith Stein, embora diversos outros pudessem ser incluídos em reflexões mais extensas. A escolha dos temas da individualidade, emoções e valores são igualmente importantes para a área da educação, na medida em que atravessam o processo educativo dificultando ou contribuindo para a aprendizagem e a formação de si.

Levando em conta que as situações de vulnerabilidade social ou emocional do adolescente acentuam seus os conflitos psicológicos, o filme traz um ponto de contato, tanto para o ambiente educacional, objeto de algumas reflexões de Edith Stein, quanto para a própria delinquência e subdesenvolvimento da sociedade brasileira, a partir da abstração de certos fatores em comum, trazidos nos comportamentos das cenas recortadas. Com isso, a realização de pesquisas in loco utilizando as temáticas levantadas é uma alternativa para entender como a obra de Edith Stein pode reverberar em contextos nacionais específicos.

Em suma, o desenvolvimento humano não pode ser pensado sem uma noção de estruturação, e a adolescência é um primeiro período de maior liberdade e escolha no qual as influencias sociais e culturais, somadas às influências corporais e da afetividade, se juntam ao centramento do espírito para uma caracterização mais acentuada e perdurável da pessoa em sua formação e interioridade. 


\section{REFERÊNCIAS}

BAUNGART, Thais; AMATUZZI, Mauro. Experiência Religiosa e Crescimento Pessoal: Uma Compreensão Fenomenológica. Revista de Estudos da Religião, São Paulo, v. 7 n. 2, p. 95-III, dezembro. 2007. Disponível em: $\langle$ www.pucsp.br/rever/rv4_2007/i_baungart.pdf $\rangle$. Acesso em: 25 set. 2019.

BELLO, Angela. Introdução à fenomenologia. ı. ed. São Paulo: EDUSC, 2006. ro8p.

. O Sentido do Sagrado. I. ed. São Pulo: Paulus, 2019. 158p.

BLACKBOARD JUNGLE. Direção: Richard Brooks. [S.I], Metro-GoldwynMayer, 1955. Mídia digital.

BOCK, Ana. A adolescência como construção social: estudo sobre livros destinados a pais e educadores. Revista Semestral da Associação Brasileira de Psicologia Escolar e Educacional (ABRAPEE), São Paulo, vol. II, n.I, p. 63-76, 2007. Acesso em: 〈http://www.scielo.br/pdf/pee/virnI/vinnia07〉. Acesso: outubro 2019.

CHARACTER. In: APA DICTIONARY OF PSYCHOLOGY. Washignton DC, American Psychological Association, 2020a. Disponível em: 〈https://dictionary.apa.org/character〉. Acesso em: I2 out. 202I

CHARACTER. Wiktionary, 202I. Disponível em: <https://en.wiktionary.org/wiki/character> Acesso em I5 nov. 202I

EMOTION. In: APA DICTIONARY OF PSYCHOLOGY. Washignton DC, American Psychological Association, 2020b. Disponível em: 〈https://dictionary.apa.org/emotion〉. Acesso em: I2 out. 202I

ESPÍNDULA, Joelma. O significado da religiosidade para pacientes com câncer e para profissionais de saúde. 2019. 230p. Tese (doutorado em enfermagem psiquiátrica) - Escola de Enfermagem de Ribeirão Preto da Universidade de São Paulo, Universidade de São Paulo, Ribeirão Preto, 2009. Disponível em: <https://teses.usp.br/teses/disponiveis/22/22131/tde-o8or2oro123832/publico/JoelmaAnaEspidula.pdf >. Acesso em: 15 out. 2019.

GOTO, Tommy; GARCIA, Aparecida. A presença do pensamento de Edith Stein no Brasil: do começo até os anos de 2012. In: V Convegno Internazionale di Fenomenologia. Bari, Universidade de Bari, 2012. Disponível em: $\langle$ http://editora.pucrs.br/anais/seminario-internacional-de-antropologiateologica/assets/2016/6.pdf >. Acesso em: i6 out. 2019.

HALL, Calvin; LINDZEY, Gardner; CAMPBELL, John. Teorias da personalidade. 4. Ed. Porto Alegre, Artmed, 2007. 578p. 
IBGE - INSTITUTO BRASILEIRO DE GEOGRAFIA E ESTATÍSTICA. Síntese de Indicadores Sociais 2020: Educação. Brasil: IBGE, 2020. Disponível em: <https://www.ibge.gov.br/estatisticas/sociais/educacao/922I-sintese-de-indicadoressociais.html? $=\& \mathrm{t}=$ downloads $>$. Acesso em: or out. 2021

KUSANO, Mariana. A antropologia de Edith Stein: entre Deus e a filosofia. izo p. Dissertação (Mestrado) - Mestrado em Ciências da Religião, PUC-SP, São Paulo, 2009. Disponível em: 〈https://tede2.pucsp.br/handle/handle/2136〉. Acesso em: is out. 2019.

LICKONA, Thomas. Eleven Principles of Effective Character Education. Journalof Moral Education n. 25, v.I, p. 93-100, 1996. Disponível em: $\langle$ https://philpapers.org/rec/LICEPO〉. Acesso em: I7 out. 202I

NUNES, Etelvina. Constituição do Outro e de Si Mesmo a partir da Einfûnhlung em Edith Stein. Ideas y Valores, vol. LXVIII, núm. I7I, pp. I05-I2I, 2019. Disponível em: 〈https://www.redalyc.org/journal/809/80962732005/html/> Acesso em: o7 out. 202I

PAPALIA, Diane; FELDMAN, Ruth. Desenvolvimento humano. Trad: Carla Filomena Marques Pinto Vercesi, et al.; 12. ed. Porto Alegre, AMGH, 2013.

PENAFRIA, Manuela. Análise de Filmes - Conceitos e Metodologia(s). Lisboa, VI Congresso SOPCOM, abr. 2009. Acesso em: or out. 2021

PENNA, Antonio. Introdução a psicologia fenomenológica. I. ed. Rio de Janeiro, Imago, 2001. 120p.

PERES, Savio. A concepção de motivação no pensamento de Edith Stein. Rev. abordagem Gestalt. Goiânia , v. 25, n. 3, p. 294-30I, dez. 2019 . Disponível em <http://pepsic.bvsalud.org/scielo.php?script=sci_arttext\&pid=SI809-

$68672019000300008 \& \operatorname{lng}=$ pt\&nrm=iso $>$. Acesso em: ol out. 2021

PERSONALITY. In: APA DICTIONARY OF PSYCHOLOGY. Washignton DC, American PsychologicalAssociation, 2020c. Disponível em: <https://dictionary.apa.org/personality>. Acesso em: 12 out. 202I

PERLSTEIN, Daniel. Imagined Authority: Blackboard Jungle and the Project of Educational Liberalism, Paedagogica Historica, 36:1, 407-424, 2000. Disponível em:<https://www.researchgate.net/publication/24051754I_Imagined_Authority_Blac kboard_Jungle_and_the_Project_of_Educational_Liberalism>. Acesso em: or out. 202I

SBERGA, Adair. A Formação da Pessoa em Edith Stein. I. Ed. São Paulo, Paulus, 2015. 219p. 
SCARANTINO, Andrea; SOUSA, Ronald. Emotion In: The Stanford Encyclopedia of Philosophy, 202I. Disponível em: 〈https://plato.stanford.edu/archives/sum202I/entries/emotion/〉. Acesso em: or out. 2021

SENNA, Sylvia; DESSEN, Maria. Contribuições das Teorias do Desenvolvimento Humano para a Concepção Contemporânea da Adolescência. Psicologia: Teoria e Pesquisa, v. 28, n. I, p. IOI-I08, 20I2. Disponível em: <https://www.scielo.br/j/ptp/a/fpKByLWpTT8BY4YvgkRH6pB/?lang=pt\&forma $\mathrm{t}=\mathrm{pdf}>$ Acesso em: 22 nov. 2021

SHARKEY, Sarah. Thine Own Self: individuality on Edith Stein's later writings. I ed. Washinton DC: The Catholic University of America Press, 2010. 289p.

SILVA, Cleiry; ESPÍNDULA; Joelma; SILVA, Paulo. Contribuições da fenomenologia de Husserl e Stein para a atuação da enfermagem para a saúde do homem. In: ESPÍNDULA, Joelma. Psicologia fenomenológica e saúde: teoria e pesquisa. Boa vista: EDUFRR, 2019. p.99-II4.

SILVA, Nara. Saúde mental na estratégia saúde da família: uma compreensão a partir da fenomenologia de Edith Stein. 2011.209 p. Tese (doutorado em psicologia) Departamento de Psicologia e Educação, Universidade de São Paulo, Ribeirão Preto, 201I. Disponível em: <https://teses.usp.br/teses/disponiveis/59/59137/tde-21102013151555/publico/tesenarahlpsilva.pdf>. Acesso em: I6 out. 2019.

STEIN, Edith. Contribuciones a la fundamentacion filosófica de la psicología y de las ciencias del espíritu. In: URKIZA, Julen; SANCHO, Francisco (org). Obras completas II: escritos filosóficos. Tradução Constantino Ruiz Garrido e José Luis Caballero Bono. Burgos: Editorial Monte Carmelo, 2006. p. 207-334 (original de 1922)

- Philosophy of Psychology and the Humanities.Washington D.C: ICS Publications, 2000. 430p. (original de 1922)

. Sobre el Problema da la Empatía. In: URKIZA, Julen; SANCHO, Francisco (org). Obras completas II: escritos filosóficos. Tradução Constantino Ruiz Garrido e José Luis Caballero Bono. Burgos: Editorial Monte Carmelo, 2006. p. 55-203 (original de 1917)

Structura de la Persona Humana. In: In: URKIZA, Julen; SANCHO, Francisco (org). Obras completas IV: escritos antropológicos e pedagógicos. Tradução Constantino Ruiz Garrido e José Luis Caballero Bono. Burgos: Editorial Monte Carmelo, 2003. p.56o-749 (original de 1932-1933) 
SZANTO, Thomas; MORAN, Dermot. Edith Stein In: The Stanford Encyclopedia of Philosophy, 2020. Disponível em: $\langle$ https://plato.stanford.edu/archives/spr2020/entries/stein/〉. Acesso em: or out. 2021

VALUE. In: APA DICTIONARY OF PSYCHOLOGY. Washignton DC, American Psychological Association, 2020d. Disponível em: <https://dictionary.apa.org/value〉. Acesso em: I2 out. 202I

XAVIER, Alessandra; NUNES, Ana. Psicologia do Desenvolvimento. 4 ed. rev. e ampl. Fortaleza, EdUECE, 2015. I6sp.

ZAPPE, Jana. Adolescência, ato infracional e processos de identificação: um estudo de caso com adolescentes privados de liberdade. 20ı, I48p. Dissertação (mestrado em Psicologia da Saúde) - Centro de Ciências Sociais e Humanas, Universidade Federal de Santa Maria, Santa Maria, 2010. Disponível em: <https://repositorio.ufsm.br/bitstream/handle/I/ro298/DIS_PPGPSICOLOGIA_20 II_ZAPPE_JANA.pdf?sequence $=\mathrm{I} \&$ is Allowed $=\mathrm{y}>$ Acesso em: 22 nov. 202I. 